\title{
Surgical repair of subaortic stenosis resection: 10 years of single-center experience in 65 patients
}

\author{
Yuefeng $\mathrm{Cao}^{1}$, Shuang Yang ${ }^{1}$, Wenxiu $\mathrm{Li}^{1}$, Lei $\mathrm{Li}^{2}$, Junwu $\mathrm{Su}^{2}$, and Xiangming Fan ${ }^{2}$ \\ ${ }^{1}$ Affiliation not available \\ ${ }^{2}$ Pediatric Cardiac Center, Beijing Anzhen Hospital, Capital Medical University, No. 2 \\ Anzhen Rd, Chaoyang District, Beijing 100029, China.
}

May 17, 2021

\begin{abstract}
Abstract Background Subaortic stenosis (SAS) was a rare congenital heart disease of left ventricular outflow tract (LVOT), ranging from "isolated" lesions to "tunnel" or "diffuse" lesions. We conducted a retrospective study to describe the characteristics of patients with different lesions and analyze the risk factors for reoperation. Methods In this study, we examined a single-center retrospective cohort of SAS patients undergoing resection from 2010 to 2019. Patients were classified as simple lesion group $(\mathrm{n}=37)$ or complex lesion group $(\mathrm{n}=28)$. Demographics, perioperative findings, and clinical data were analyzed. Results The surgical effect of the two groups was significantly lower than that before the operation $(\mathrm{p}<0.05)$. The median age at operation was 6(3-11.8) years. There was no operative mortality. In complex lesion group, extracorporeal circulation time (CPB time), aortic cross clamp time (ACC time), mechanical ventilation time and ICU stay time were longer. The median follow-up period was 2.8 years (range 1-3.8), with two late death. Six patients (9.2\%) required reoperation due to restenosis or severe aortic insufficiency. The freedom from reoperation rates at 5 years was $66.7 \%$ for simple lesion but only $52.3 \%$ for complex lesion $(\mathrm{p}=0.036)$. Conclusions Although the lesions include many forms, subaortic stenosis resection was still satisfactory. However, the reoperation after initial surgical treatment was not infrequent, especially in patients with complex lesion.
\end{abstract}

\section{Hosted file}

main document.pdf available at https://authorea.com/users/414255/articles/522332-surgicalrepair-of-subaortic-stenosis-resection-10-years-of-single-center-experience-in-65patients

\section{Hosted file}

Table 1 The baseline characteristics.pdf available at https://authorea.com/users/414255/ articles/522332-surgical-repair-of-subaortic-stenosis-resection-10-years-of-singlecenter-experience-in-65-patients

\section{Hosted file}

Table2 Characteristics of patients with reoperation after SAS resection.pdf available at https://authorea.com/users/414255/articles/522332-surgical-repair-of-subaortic-stenosisresection-10-years-of-single-center-experience-in-65-patients 


\section{Simple}

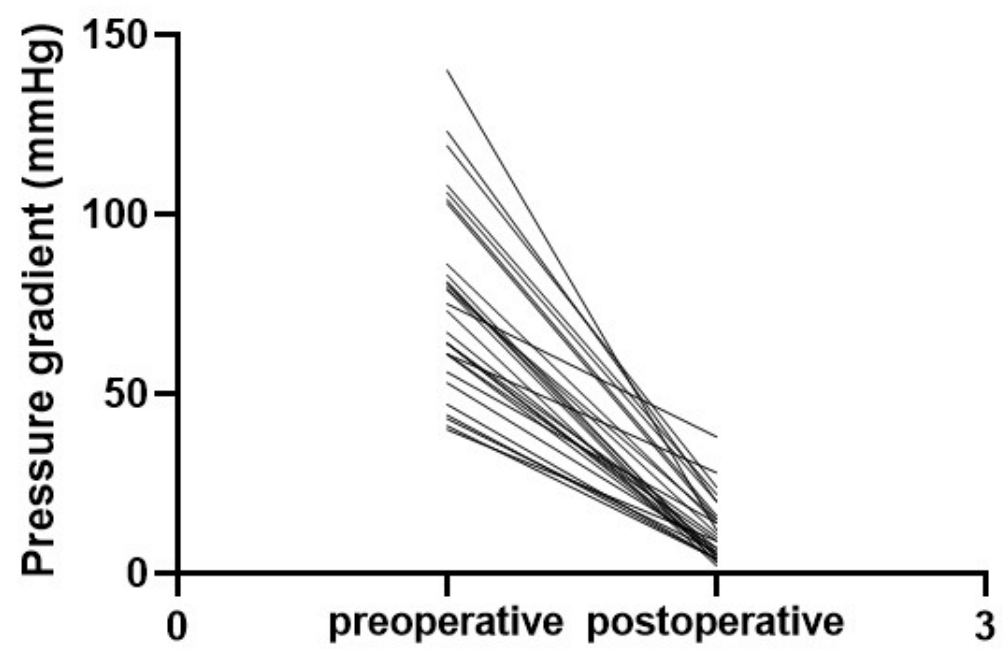

\section{Complex}

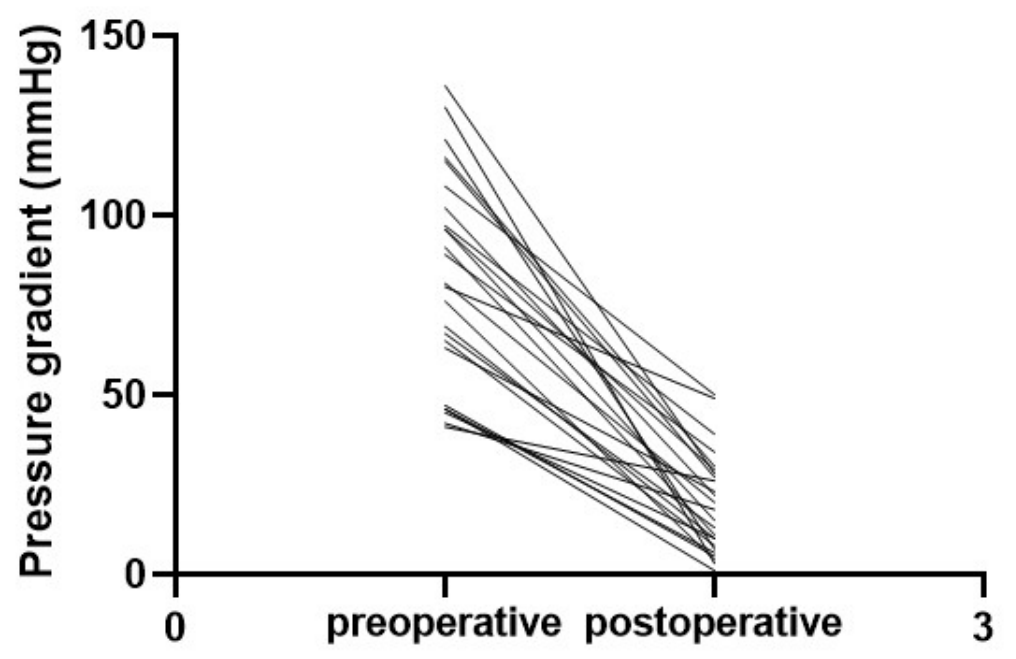




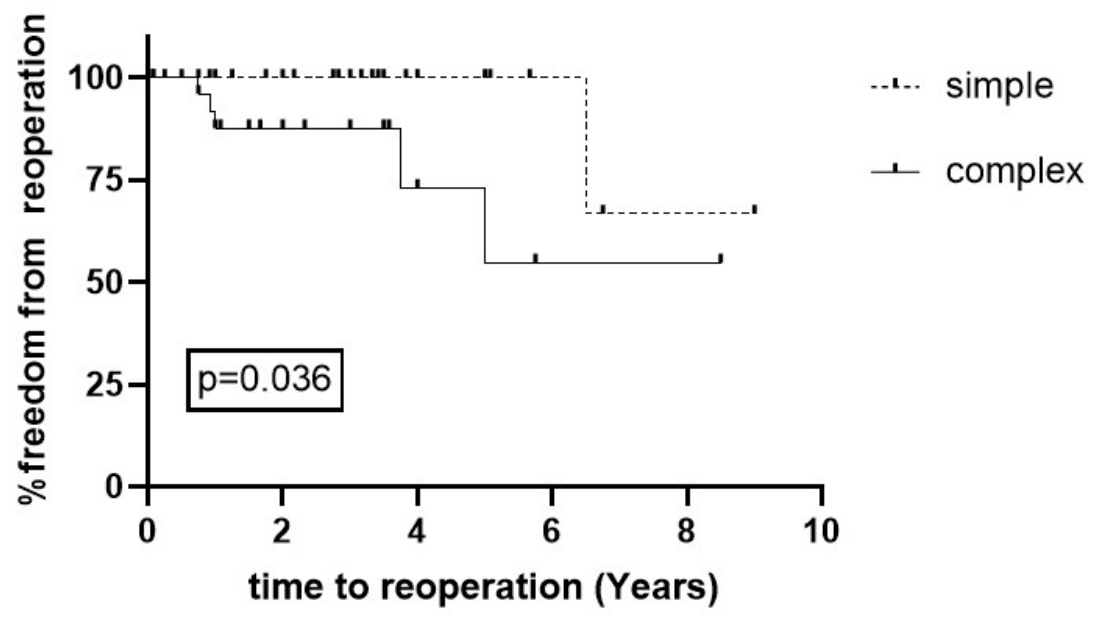

